\title{
ASPECTS OF COMPLEXITY OF METAL-FIBROUS MICROSTRUCTURE FOR THE CONSTRUCTION OF HIGH-PERFORMANCE HEAT EXCHANGERS: THERMAL PROPERTIES
}

\author{
Łukasz J. ORMAN (1D* \\ Faculty of Environmental, Geomatic and Energy Engineering, Kielce University of Technology, Kielce, Poland
}

Received 08 June 2019; accepted 02 January 2020

\begin{abstract}
The paper considers the application of metal - fibrous microstructures in the development of highly efficient heat exchangers. Such structures can be successfully used in air conditioning systems of modern planes or in heat pipes located in planes and spacecraft. Copper fibers of $50 \mu \mathrm{m}$ diameter have been used to produce coatings of different volumetric porosity. The sintering process was used to produce the samples. Pool boiling heat transfer tests have been performed on the non - isothermal surfaces of the fin with distilled water and ethyl alcohol ( $99.8 \%$ purity) as boiling agents. A significant enhancement of heat transfer has been recorded with the use of the metal - fibrous microstructures in comparison to the smooth surface without any coating. The enhancement proved to vary considerably depending on the superheat value.
\end{abstract}

Keywords: aircraft anti-icing, boiling heat transfer, enhancement, heat pipes, metal - fibrous microstructures.

\section{Introduction}

Phase - change heat exchangers are widely used in many areas of engineering e.g. in refrigeration and air conditioning systems or cooling of electronic devices. Their proper design influences the performance of the devices and machines, in which they are installed. The properties of heat exchangers working under boiling conditions are highly dependent on the geometric parameters of the surface. The application of additional microstructures such as meshes, microfins, metal - fibrous and other coatings may significantly improve their performance and provide higher heat fluxes dissipated at lower temperature differences, thus, increasing the efficiency of the devices. The present paper discusses the use of metal - fibrous microstructures and the enhancement of boiling heat transfer, which is offered as a result of their application.

In modern aviation the metal - fibrous microstructures have two important applications. The first one is their possible use for the construction of efficient heat exchangers of air conditioning units. Such systems are responsible for providing proper air parameters (mainly temperature). The novel design of such heat exchangers that utilizes metal - fibrous elements means that they can be more efficient. Thus, those devices may be smaller and lighter, which results in reduced fuel consumption of planes. Besides, metal - fibrous microstructures are used as an internal filling of heat pipes. The heat pipes are highly efficient and reliable phase - change heat exchangers that are already commonly used in spacecraft as presented by Shukla (2015). They can also be very effective as aircraft anti-icing systems, as discussed by Su et al. (2018). Consequently, the knowledge about the thermal performance of metal - fibrous microstructures - which is the focus of this paper - can lead to the design of novel heat exchangers, whose practical applications are not limited to planes or spacecraft, but also to other fields of engineering and technology.

Zaripov et al. (1989) experimentally analysed boiling heat transfer of water, nitrogen and acetone on copper and stainless steel isothermal surfaces $30 \mathrm{~mm}$ in diameter. Porous coatings made of copper, steel and nickel fibers were tested. The structure porosity ranged from $40 \%$ to $93 \%$, while their height varied from $0.1 \mathrm{~mm}$ to $10 \mathrm{~mm}$. The fiber diameter was $20-70 \mu \mathrm{m}$ and length 3-9 $\mathrm{mm}$. It was confirmed that there is an optimal structure height, at which the heat transfer coefficient is highest. Theoretical analysis of Fridrikhson, Kravets, and Semena (1994) led to a procedure to calculate the density of active nucleation sites during boiling on porous coatings, which - according to the authors - exerts a considerable influence on heat transfer, and a correlation for metal - fibrous structures. Poniewski (2001) presented boiling heat transfer test results for water, ethanol and R-113 on horizontal isothermal

*Corresponding author. E-mail: orman@tu.kielce.pl 
surfaces with copper fibrous structures of fiber diameter $50 \mu \mathrm{m}$ and length $3 \mathrm{~mm}$. It was reported that the coating parameters significantly influence heat transfer. The existence of an optimal layer height for a given porosity was confirmed. The heat transfer coefficient for water boiling on a sample of $85 \%$ porosity at the pressure of $0.1 \mathrm{MPa}$ was highest for the $0.8 \mathrm{~mm}$ structure height and was 5.5 times higher than for the smooth surface at the same heat flux. Considering the combined impact of porosity and height on the heat transfer coefficient, it was stated that after the optimal value for the given porosity is reached, this coefficient decreases with increasing layer height, which is explained by higher vapour flow resistance. Wójcik (2005) investigated water boiling heat transfer on a horizontal isothermal tube of the diameter of $19 \mathrm{~mm}$ covered with a copper - fibrous microstructure of $40 \%$ porosity and height $0.5-2.0 \mathrm{~mm}$. The coating was produced with fibers of $50 \mu \mathrm{m}$ diameter and $3 \mathrm{~mm}$ long. Similarly to his earlier work (Wójcik, 2004) a significant enhancement was recorded for the porous structures - the highest for the layer height of $2 \mathrm{~mm}$. Another paper by Wójcik (2009) experimentally analyses boiling heat transfer of copper, fibrous layers with the focus on the hysteresis phenomena, which is evident if the boiling curves are obtained for increasing and decreasing heat fluxes. Kalawa et al. (2017) tested pool boiling of distilled water heat transfer on horizontal isothermal surfaces covered with coatings made of stainless steel fibers. The average diameter of the fibers was $10 \mu \mathrm{m}$ and $25 \mu \mathrm{m}$. It was reported that the microstructural coating enhanced heat transfer in comparison to the smooth surface - heat flux for the superheat of $10 \mathrm{~K}$ was ca. 3.5 higher than for the smooth surface (in the case of fibers of $25 \mu \mathrm{m}$ diameter). It was also stated that the larger diameter of fibers led to the larger heat transfer coefficients at smaller heat flux.

The literature provides experimental data on boiling heat transfer on isothermal surfaces. Only the few works

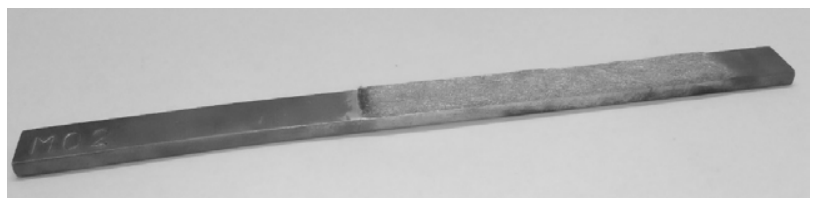

Figure 1. The fin with the fibrous layer

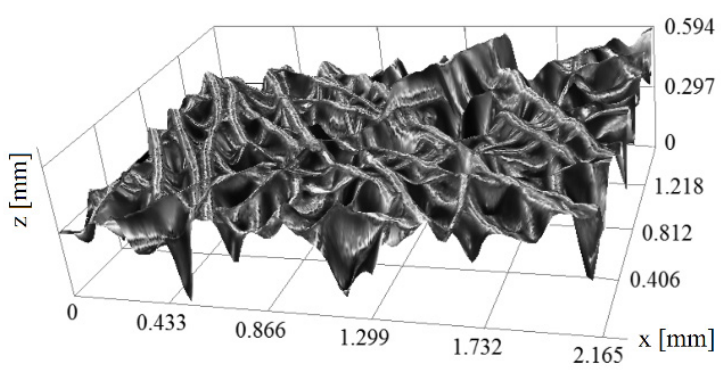

Figure 2. Microgeometry profile of the metal - fibrous coating measured with a 3D digital microscope by Orzechowski (2003), Orzechowski and Orman (2006) as well as some papers of these authors deal with pool boiling on non-isothermal surfaces of different microstructural coatings. Thus, there is a need to expend the experimental database regarding the analysis of porous metal - fibrous coatings, especially due to the fact that heat exchangers found in engineering applications are usually non-isothermal.

\section{Material and method}

The experiments have been performed to determine the performance of a non - isothermal heat exchanger covered with copper fibrous microstructures of different porosity ( $67 \%$ and $81 \%)$, but the same structure height of ca. $0.9 \mathrm{~mm}$. The coatings were produced with copper fibers of $50 \mu \mathrm{m}$ diameter sintered to the copper fin (Figure 1) at the temperature of ca. $1170 \mathrm{~K}$ in the reduction atmosphere of nitrogen and hydrogen to prevent oxidation. The fin's width is $4 \mathrm{~mm}$ and height $12 \mathrm{~mm}$. Figure 2 presents the close-up of the microstructure of the produced porous layer.

The considered fin is located horizontally in the experimental stand in such a way that the mesh is in contact with the boiling liquid, while the other side is open to the atmosphere and can be observed with a thermovision camera (Figure 3). The main heater is attached to the fin at one end (the one without the microstructure). Together with the additional heater, it warms it up to temperatures over the saturation temperature. Because heat is supplied to only one end of the fin, the temperature gradient along it is created. The temperature distribution is then measured with a long - wave $(8-14 \mu \mathrm{m})$ thermovision camera. The obtained temperature distribution is used to draw boiling curves. That is done according to the method presented

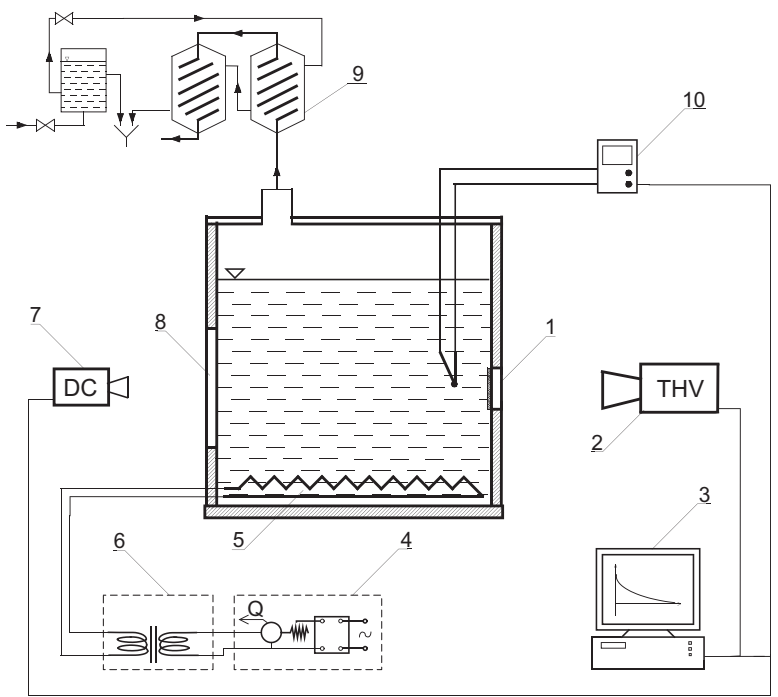

Figure 3. Schematic of the experimental stand: 1 - fin, 2 - infrared camera, 3 - data acquisition unit, 4 autotransformer, 5 - auxiliary heater, 6 - electrical current separation unit, 7 - digital camera, 8 - window, 9 - cooling unit, 10 - temperature measuring device (Orzechowski \& Orman, 2006) 
by Orzechowski (2003) and already used by the author e.g. in (Chatys et al. 2014). In this method the heat transfer coefficient $(\alpha)$ depends exponentially on superheat $(\theta)$ (which is the difference between the wall temperature and the saturation temperature):

$$
\alpha=a \theta^{n} .
$$

The experimental determination of constants: $a$, and $n$ leads to the equation for the boiling curve. According to the methodology (Orzechowski, 2003) the formula for superheat gradient along the fin in logarithmic coordinates can be expressed as:

$$
\ln \left(\frac{d \theta}{d x}\right)^{2}=\ln \left(\frac{2 m^{2}}{n+2}\right)+(n+2) \ln \theta,
$$

while $\mathrm{n} \neq 2$ and $\mathrm{m}^{2}$ is defined as the ratio:

$$
m^{2}=\frac{a P}{\lambda F} \text {. }
$$

Here $P$ and $F$ are the circumference and surface area of the copper fin, respectively. $\lambda$ is the thermal conductivity of the material.

The knowledge about the temperature distribution along the fin (after numerical differentiation) enables the constants and $n$ to be determined from the data fitting procedure. As a result, the boiling curve can be drawn as a function of local values of heat transfer coefficient (or heat flux) and wall superheat using equation (1).

The experiments are conduced under ambient pressure, while the liquid level in the vessel is maintained at the constant level due to the use of the cooling unit (no 9 in Figure 3). The replacement of the samples in quite complex and each time proper sealing needs to be ensured at the contact surfaces with the bakelite plates of the vessel (rubber sealing is used here). The measurements are done for three level of the electric power supplied to the main heater, while its adjustment is done with the autotransformer. Thus, different areas of the fin and subject to rising temperatures. The auxiliary heater (no 5 in Figure 3) is also supplied with the autotransformer. It maintains the temperature of the boiling liquid at the constant level for the whole experiment (which is the boiling temperature of the liquid).

Two measuring instruments have been used in the research. The main one is the thermovision camera produced by Flir, which is used for the determination of temperature distribution along the fin. The provided measuring accuracy has been given as $2 \%$ of the measuring range. However, in order to reduce the error, the surface of the observed fin was covered with a special purpose black paint. The emissivity of this paint was determined on a separate experimental stand, where surface temperature was determined with both the infrared camera and the thermocouple. Based on this additional calibration, the temperature reading of the infrared measurement has been determined as $0.2 \mathrm{~K}$ (twice higher than the thermal sensitivity of the device of $0.1 \mathrm{~K}$ ). The data processing involved numerical differentiation of the obtained temperature gradient (with smoothing), so that the constants could be determined (according to equation 2). This process involves increasing the overall uncertainty. In order to conduct the error analysis of the value of heat transfer coefficient, a procedure based on adding random errors to the "real" temperature readings has been performed. Based on this, the uncertainty of determining heat transfer coefficient has been assessed to be $8 \%$ in the whole range of temperature measurements. The temperature of the boiling liquid has been determined with a K type thermocouple connected to the multimeter by Keithley. The accuracy of the reading (if the ice bath system is used to provide the reference temperature point) is $\pm 0.2 \mathrm{~K}$ as already mentioned. The details of the selected experimental parameters have been provided in Table 1.

Before the actual measurements, the results obtained at the above mentioned experimental stand had to be compared with the data from other researchers to validate the correctness of the research apparatus. Figure 4 presents the comparison of the test results of the smooth surface (distilled water as the boiling liquid) and the literature data namely, models and experimental data from: Rohsenow (1952) with the constants determined by Pioro (1999), Stephan and Abdelsalam (1980), Xin and Chao (1987), Zhao and Zhang (1988), Li, Peterson, and Wang (2006) as well as Li and Peterson (2006).

As can be seen in the above figure, the results obtained in the presented method are close and within the data published by other researchers. This proves the correctness of this method of testing, despite the fact that all the other papers dealt with isothermal surfaces.

Table 1. Details of the measuring devices

\begin{tabular}{|l|c|c|}
\hline Device & $\begin{array}{c}\text { Temperature } \\
\text { measurement } \\
\text { uncertainty }\end{array}$ & $\begin{array}{c}\text { Other measurement } \\
\text { parameters }\end{array}$ \\
\hline $\begin{array}{l}\text { Infrared } \\
\text { camera }\end{array}$ & $\begin{array}{c}2 \% \text { (reduced to } \\
0.2 \mathrm{~K})\end{array}$ & $\begin{array}{c}\text { Infrared resolution: } 19200 \text { pixs } \\
\text { Thermal sensitivity: 0.1K }\end{array}$ \\
\hline $\begin{array}{l}\text { Multi- } \\
\text { meter }\end{array}$ & $0.2 \mathrm{~K}$ & K type thermocouple \\
\hline
\end{tabular}

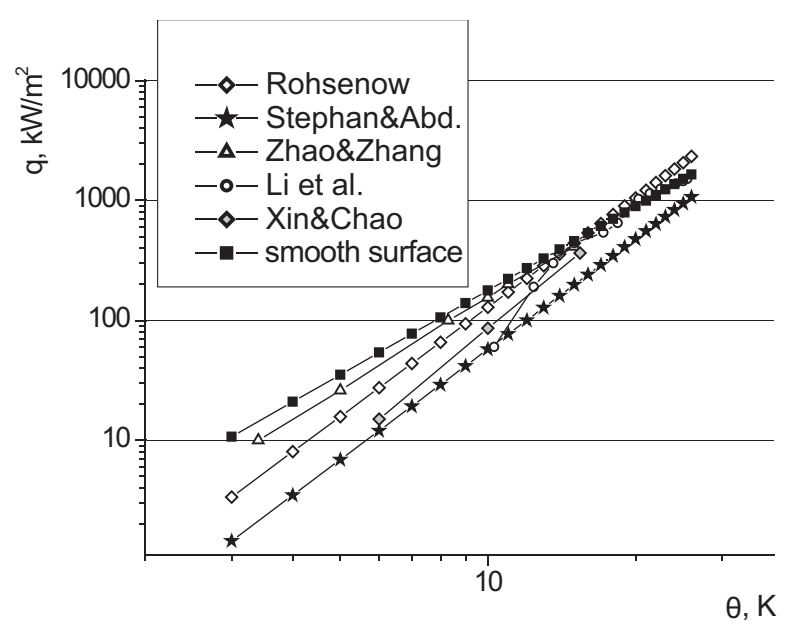

Figure 4. Comparison of the test results and literature data 


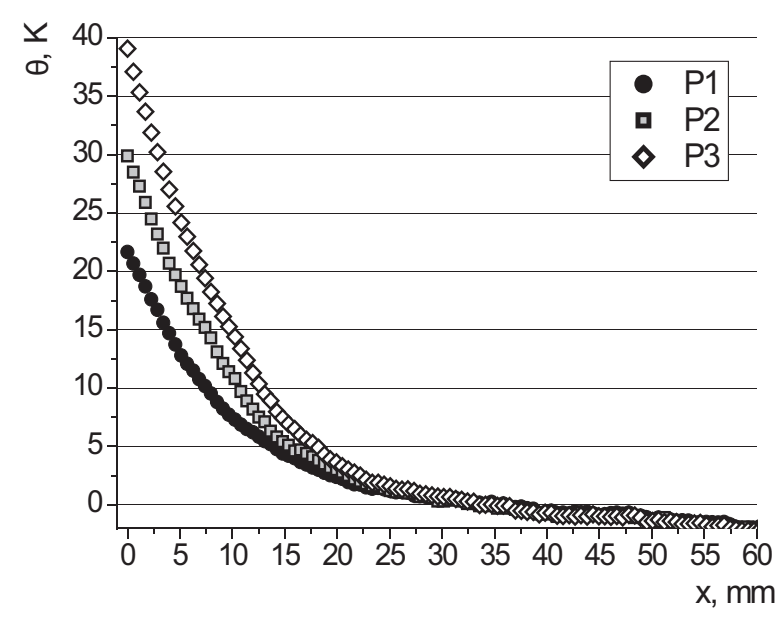

Figure 5. Temperature distribution along the fin for three levels of electric power $(\mathrm{P})$ supplied to the main heater: metal - fibrous sample of $67 \%$ porosity; distilled water boiling

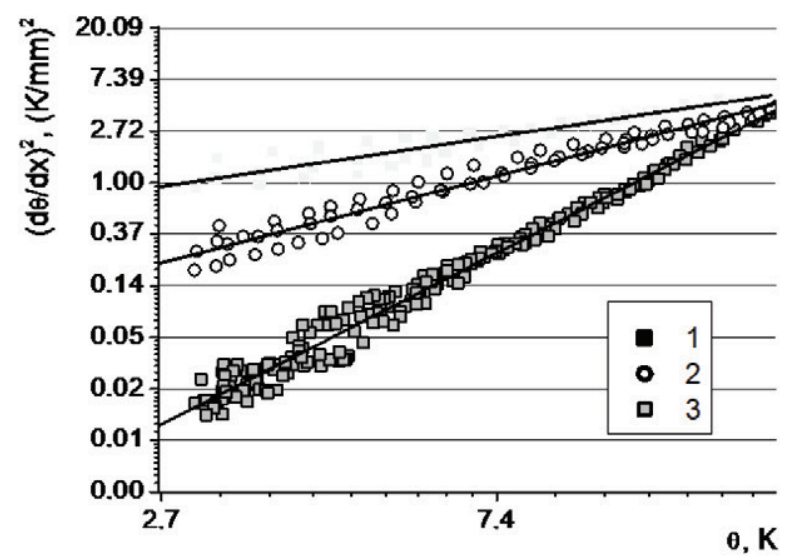

Figure 6. Superheat gradient vs. superheat for the porous coatings and the smooth surface $(3 \mathrm{~K}<\theta<17 \mathrm{~K})$; distilled water boiling: 1 - metal-fibrous microstructure of $81 \%$ porosity, 2 - metal-fibrous microstructure of $67 \%$ porosity, 3 - smooth surface



Figure 7. Superheat gradient vs. superheat for all the porous coatings and the smooth surface $(8 \mathrm{~K}<\theta<20 \mathrm{~K})$; ethyl alcohol boiling: 1 - metal-fibrous microstructure of $81 \%$ porosity, 2 - metal-fibrous microstructure of $67 \%$ porosity, 3 - smooth surface

\section{Test results and discussion}

The measurements were carried out for two porous microstructures of different porosity (67\% and $81 \%$ ) in order to determine the impact of porosity on boiling heat transfer. The working fluids have been distilled water and ethyl alcohol ( $99.8 \%$ purity).

The tests began with recording the temperature distributions along the fin. It was done with the thermovision camera for three different levels of electric power. Figure 5 presents the temperature gradient for the sample of lower porosity.

Due to numerical differentiation of the obtained temperature readings of all the samples in the present study, the first derivative values could have been calculated. This has been presented in Figures 6 and 7 for the porous coatings and the smooth reference surface (without any coating) for distilled water and ethyl alcohol, respectively.

The constants $a$ and $n$ could have been determined according to equation (2) through the least square fitting

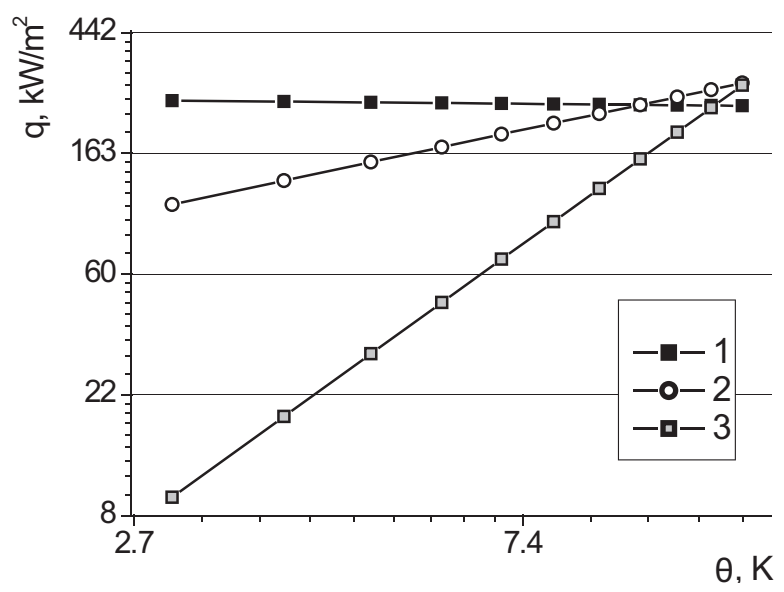

Figure 8. Boiling curves for distilled water $(3 \mathrm{~K}<\theta<13 \mathrm{~K})$; 1 - metal-fibrous microstructure of $81 \%$ porosity, 2 - metalfibrous microstructure of $67 \%$ porosity, 3 - smooth surface

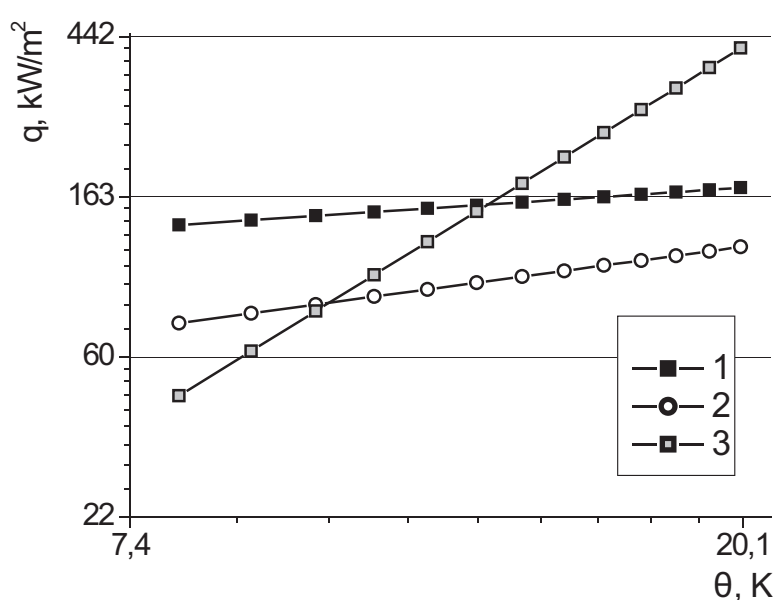

Figure 9. Boiling curves for ethyl alcohol $(8 \mathrm{~K}<\theta<17 \mathrm{~K})$; 1 - metal-fibrous microstructure of $81 \%$ porosity, 2 - metalfibrous microstructure of $67 \%$ porosity, 3 - smooth surface 
of the experimental points. Then the boiling curves could have been drawn for both boiling liquids (Figures 8 and 9) using linear regression for both the liquids. A close analysis of the above figures proves that the thermal performance of the microporous coatings is much better than the smooth surface, especially in the range of low superheat values. For higher temperature differences the data points of the metal - fibrous layers get close to the results of the smooth reference surface. This phenomenon is typical of the porous coatings. It needs to be noted, however that the sample of higher porosity provides better performance that the lower porosity one. Thus, such a heat exchanger is more efficient in dissipating significant heat flux values. One of the possible explanation is the present of more active nucleation sites in the case of the sample of $81 \%$ porosity. The boiling curves produced below have been given for superheats of $3-13 \mathrm{~K}$ for distilled water and $8-17 \mathrm{~K}$ for ethyl alcohol.

As can be clearly seen in Figures 8 and 9 the largest enhancement of heat transfer is observed for low superheats and high porosity of the microstructure as already mentioned. The increase in temperature of the surface leads to more nucleation sites being active on the smooth surface, which begins to provide better performance. At the same

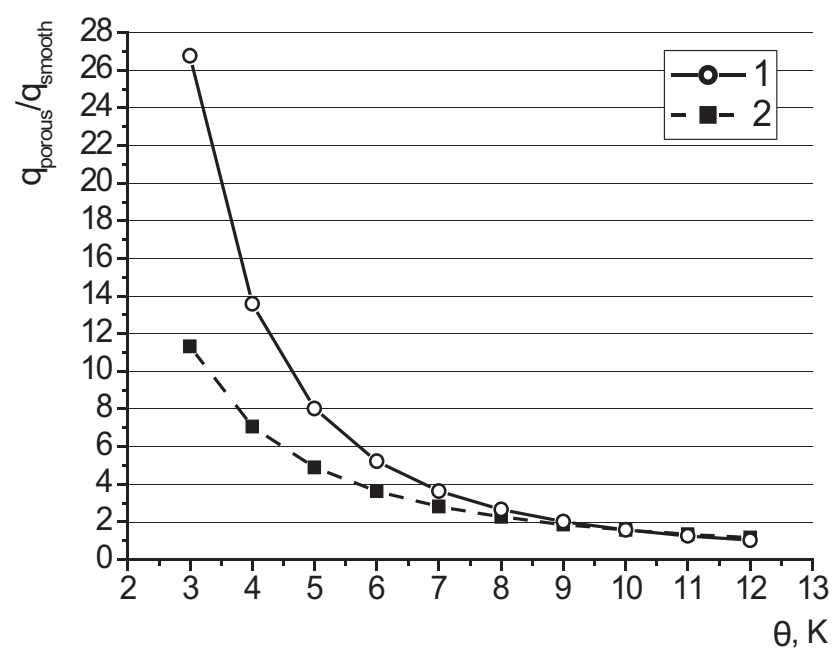

Figure 10. Enhancement ratio for distilled water boiling $(3 \mathrm{~K}<\theta<12 \mathrm{~K}) ; 1$ - metal-fibrous microstructure of $81 \%$ porosity, 2 - metal-fibrous microstructure of $67 \%$ porosity

Table 2. Comparison of the experimental and selected literature data for the sample of highest porosity

\begin{tabular}{|c|c|c|c|c|}
\hline $\begin{array}{l}\text { Boiling } \\
\text { liquid }\end{array}$ & \multicolumn{2}{|c|}{$\begin{array}{c}\text { Experimental data: } \\
81 \% \text { porosity, } \\
0.9 \mathrm{~mm} \text { height }\end{array}$} & \multicolumn{2}{|c|}{$\begin{array}{c}\text { Data from literature: } \\
\text { Wójcik (2009) } \\
85 \% \text { porosity, } \\
0.8 \mathrm{~mm} \text { height }\end{array}$} \\
\hline \multirow{3}{*}{$\begin{array}{l}\text { Distilled } \\
\text { water }\end{array}$} & $\theta, \mathrm{K}$ & $\mathrm{Q}, \mathrm{W} / \mathrm{m}^{2}$ & $\theta, \mathrm{K}$ & $\mathrm{Q}, \mathrm{W} / \mathrm{m}^{2}$ \\
\hline & 8 & 244947 & 8 & 101268 \\
\hline & 11 & 242693 & 11 & 173594 \\
\hline \multirow{2}{*}{$\begin{array}{l}\text { Ethyl } \\
\text { alcohol }\end{array}$} & 11 & 148060 & 11 & 80153 \\
\hline & 20 & 172231 & 20 & 145260 \\
\hline
\end{tabular}

time more vapour is generated within the metal - fibrous structure and problems in vapour removal can occur. As a result the thermal performance worsens. Figure 10 provides detailed information on the enhancement of heat transfer in the case of water boiling and the considered porous coatings.

As indicated in the above figure, heat fluxes dissipated from the metal - fibrous microstructure can be many times higher in relation to the smooth surface. They become smaller as the temperature differences increase. Finally, the thermal performance of the metal - fibrous layers is similar to the smooth surface. It is also possible to obtain values which are lower then for the smooth surface. However, it typically occurs for higher heat fluxes and may be observed before the transition to unfavourable film boiling regime.

The obtained data for boiling on the non-isothermal surface of the fin has been compared with test results of other authors (for the same type of the porous microstructure). The data taken from literature was recorded on the isothermal surfaces, which might explain the discrepancies in both the data sets (Table 2). Besides the sample used for comparison had a slightly smaller height and larger porosity. This might also have influenced the heat flux exchanged during the tests.

It also needs to be noted that, apart from thermal performance advantages, a different problem is the complexity of producing such microstructures using the sintering process. It has been considered extensively e.g. in (Chatys, 2009) or (Chatys \& Orzechowski, 2004).

\section{Conclusions}

The application of metal - fibrous microstructures provides significant enhancement of boiling heat transfer. The exchanged heat fluxes can be much higher than in the case of smooth surfaces without any coatings. As a result such heat exchangers can be smaller and lighter. Besides, they offer higher heat transfer efficiency. Consequently, if they are installed in air conditioning units in planes, fuel consumption could be reduced. The same favourable impact applies to the use of metal - fibrous microstructures as an internal filling of heat pipes. In this case they would also increase the exchanged heat fluxes and anti-icing systems in places can be more efficient. Besides such heat pipes transfer higher heat fluxes in spacecraft applications, which is also a significant advantage.

The best performance of the analysed samples has been recorded for the material of high porosity. However, in this case especially important is the issue of insuring high strength properties for increased porosity values. This problem should be analysed in the future works in this area.

\section{Acknowledgements}

The project is supported by the program of the Minister of Science and Higher Education under the name: "Regional Initiative of Excellence" in 2019-2022 project number 025 / RID / 2018/19 financing amount PLN 12,000,000. 


\section{References}

Chatys, R. (2009). Modeling of adhesive strength of fiber - reinforced polymer-matrix composite materials. In Proceedings of International Conference Transport Means (pp. 112-115). Lithuania.

Chatys, R., Malcho, M., \& Orman, Ł. J. (2014). Heat transfer enhancement in phase-change heat exchangers. Aviation, 18(1), 40-43. https://doi.org/10.3846/16487788.2014.865930

Chatys, R., \& Orzechowski, T. (2004). Surface extension in layered structures with the use of metal meshes for heat-transfer enhancement. Mechanics of Composite Materials, 40(2), 159-168. https://doi.org/10.1023/B:MOCM.0000025490.66094.86

Fridrikhson, Yu. V., Kravets, V. Yu., \& Semena, M. G. (1994). Calculation of the density of active nucleation sites in the boiling of liquids on metal - fibrous capillary - porous structures. Journal of Engineering Physics and Thermophysics, 66(5), 534-540. https://doi.org/10.1007/BF00851717

Kalawa, W., Wójcik, T. M., \& Piasecka, M. (2017). Heat transfer research on enhanced heating surfaces in pool boiling. In Proceedings of International Conference Experimental Fluid Mechanics 2016, Mariánskè Láznè, EPJ Web of Conferences, 143, 02048. Czech Republic. https://doi.org/10.1051/epjconf/201714302048

Li, C., Peterson, G. P., \& Wang, Y. (2006). Evaporation/boiling in thin capillary wicks (I) - wick thickness effects. Journal of Heat Transfer, 128, 1312-1319. https://doi.org/10.1115/1.2349507

Li, C. \& Peterson, G. P. (2006). Evaporation/boiling in thin capillary wicks (II) - effects of volumetric porosity and mesh size. Journal of Heat Transfer, 128, 1320-1328. https://doi.org/10.1115/1.2349508

Orzechowski, T. (2003). Wymiana ciepła przy wrzeniu na żebrach $z$ mikropowierzchnią strukturalną, Kielce, Wydawnictwo Politechniki Świętokrzyskiej (in Polish).

Orzechowski, T., \& Orman, Ł. J. (2006). Boiling heat transfer on surfaces covered with copper fibrous microstructures, In Proceedings of XI International Conference Heat Transfer and Renewable Sources of Energy (pp. 613-619). Szczecin, Poland.

Pioro, I. L. (1999). Experimental evaluation of constants for the Rohsenow pool boiling correlation. International Journal of Heat and Mass Transfer, 42, 2003-2013. https://doi.org/10.1016/S0017-9310(98)00294-4
Poniewski, M. E. (2001). Wrzenie pęcherzykowe na rozwiniętych mikropowierzchniach. Kielce, Wydawnictwo Politechniki Świętokrzyskiej (in Polish).

Rohsenow, W. M. (1952). A method of correlating heat transfer data for surface boiling of liquids. Transactions of American Society of Mechanical Engineers, 74, 969-975.

Shukla, K. N. (2015). Heat pipe for aerospace applications - an overview, Journal of Electronics Cooling and Thermal Control, 5, 1-14. https://doi.org/10.4236/jectc.2015.51001

Stephan, K., \& Abdelsalam, M. (1980). Heat transfer correlations for natural convection boiling, International Journal Heat and Mass Transfer, 23, 73-87. https://doi.org/10.1016/0017-9310(80)90140-4

Su, Q., Chang, S., Zhao, Y., Zheng, H. \& Dang C. (2018) A review of loop heat pipes for aircraft anti-icing applications, Applied Thermal Engineering, 130, 528-540.

https://doi.org/10.1016/j.applthermaleng.2017.11.030

Wójcik, T. M. (2004). Boiling on cylindrical surfaces with thicklayered porous covering. In Proceedings of X Int. Symposium Heat Transfer and Renewable Sources of Energy (pp. 653-660). Szczecin - Miedzyzdroje, Poland.

Wójcik, T. M. (2009). Experimental investigations of boiling heat transfer hysteresis on sintered, metal - fibrous, porous structures. Experimental Thermal and Fluid Science, 33(3), 397-404.

https://doi.org/10.1016/j.expthermflusci.2008.10.011

Wójcik, T. M. (2005). Pool boiling heat transfer on horizontal tubes with metal, fibrous porous coverings. In Proceedings of 4th International Conference on Transport Phenomena in Multiphase Systems HEAT2005 (pp. 535-542). Gdańsk, Poland.

Zaripov, V. K., Semena, M. G., Shapoval A. A., \& Levterov, A. I. (1989). Heat-transfer rate in boiling at a surface with porous coatings in conditions of free motion. Journal of Engineering Physics, 57(2), 859-863.

https://doi.org/10.1007/BF00871767

Zhao, X., \& Zhang, H. (1988). Experimental study of pool boiling heat transfer from powder porous surface at higher heat fluxes. In Advances in Phase Change Heat Transfer (pp. 236241). International Academic Press, China.

Xin, M.-D., \& Chao, Y.-D. (1987). Analysis and experiment of boiling heat transfer on T-shaped finned surfaces. Chemical Engineering Communications, 50(1-6), 185-199. https://doi.org/10.1080/00986448708911825 